Research Article

\title{
Experimental Investigation and Analysis of Triggering Mechanism for Fault-Slip Bursts of the Tunnel Surrounding Rock with External Disturbance
}

\author{
Hai-ming Jiang $\mathbb{D},{ }^{1}$ Jie Li $\mathbb{D}^{1},{ }^{1}$ Shu-xin Deng, ${ }^{2}$ De-rong Wang $\mathbb{D}^{1},{ }^{1}$ and Xiao Zhao ${ }^{3}$ \\ ${ }^{1}$ State Key Laboratory of Disaster Prevention and Mitigation of Explosion and Impact, Army Engineering University of PLA, \\ Nanjing, Jiangsu 210007, China \\ ${ }^{2}$ School of Mechanical Engineering, Nanjing University of Science and Technology, Nanjing, Jiangsu 210094, China \\ ${ }^{3}$ College of Communication Engineering, Army Engineering University of PLA, Nanjing, Jiangsu 210007, China
}

Correspondence should be addressed to Jie Li; lijierf@163.com

Received 29 January 2018; Revised 29 June 2018; Accepted 9 July 2018; Published 25 September 2018

Academic Editor: Giosuè Boscato

Copyright ( $\odot 2018$ Hai-ming Jiang et al. This is an open access article distributed under the Creative Commons Attribution License, which permits unrestricted use, distribution, and reproduction in any medium, provided the original work is properly cited.

\begin{abstract}
Shear-slip type rockburst is one of the most common geohazards confronted in deep underground excavations, which can easily occur after external disturbances. Owing to the sudden occurrence and significant damage caused, investigating the mechanism of these shear-slip type disasters is of tremendous significance in ensuring the safety of underground construction projects. In this paper, our attentions are mainly paid to investigate the necessary conditions and critical energy conditions of fault-slip bursts of the tunnel surrounding rock triggered by external disturbances. First, a simplified model for simulating the sliding instability phenomenon occurring in a blocky rock system under external disturbance is established. Next, using a newly developed testing system for the dynamic behaviour of blocky rock masses, a series of experiments to reproduce the sliding instability phenomenon are conducted; the purple sandstone block system is subjected to the combined effect of a vertical impact load and horizontal constant force. The influence of vertical impact energy on the sliding instability is analysed. The experimental results show that the critical energy of the impact load triggering the blocky rock mass slip instability depends on the shear force, and the higher the shear force, the lower is the external disturbance required. Furthermore, a one-dimensional dynamic calculation model is established to develop a better insight regarding the mechanism of the slip instability induced by external disturbances. A dimensionless energy parameter was introduced to quantifiably characterize the critical conditions of different types of fault-slip events. Theoretical analysis and calculations are presented, and the results agree with experimental observations.
\end{abstract}

\section{Introduction}

With the depths and locations for underground engineering having become increasingly challenging, an increasing number of natural or artificial disasters have been observed, such as rockburst and excavation-induced seismicity [1-3]. Both of the above geohazards unexpectedly occur during the excavation of deeply buried tunnels and mines, accompanied with a violent and dynamic release of the residual energy of the surrounding rock masses $[4,5]$. These dynamic disasters frequently pose a serious threat to the safety of construction workers and cause the destruction of machines and equipment. For example, on November 28, 2009, an extremely severe rockburst occurred in parallel tunnels in the Jinping II hydropower station, causing the death of seven workers and majorly damaging a tunnel boring machine (TBM) that was present inside [1].

Ortlepp and Stacey [6] classified rockbursts into five types (strainburst, buckling, face crush/pillar burst, shear rupture, and fault-slip burst). In a broad sense, buckling type rockbursts can be grouped into strainbursts, and shear rupture type rockbursts can be considered as fault-slip rockbursts, thus resulting in three generalised types of rockbursts: strainbursts, pillar bursts, and fault-slip bursts $[7,8]$. Fault-slip bursts are caused by the dynamic reactivated shear on existing faults and/or shear rupture existing discontinuities [6], and the extent of this shear failure zone could be hundreds of metres. Consequently, the dynamic 
damage caused by shear-slip events is typically far more extensive than other rockbursts, as confirmed by the fact that several tens or even hundreds of metres of tunnels would be damaged in a single excavation-induced seismicity $[6,9]$. In recent years, efforts have been made to investigate shear-slip incidents caused by sliding along preexisting discontinuities or structural planes [10-17]. Although these advances have improved our understanding of shear-slip incidents, the involvement of a specific feature in dynamic failure as well as development of an effective physical calculation model has not been examined yet. Consequently, more research is required to completely understand such dynamic disasters.

In building tunnels and other open excavations, the surrounding rock mass that has a hierarchical block structure is divided by the discontinuities of different scales and is known as a "blocky rock mass" (Figure 1(a)). The interfaces of the blocky rock have a much lower effective strength and poor strain characteristics compared to the bulk material of the blocks; consequently, they exhibit strong responses, in terms of their mobility and sensitivity, to even very weak disturbances $[18,19]$. As shown in Figure 1(a), after the falling of the first blocky rock masses of a tunnel sidewall, the boundary conditions are changed, and a progressive collapse, even a shear-slip rockburst, may occur [20]. Thus, the physical nature of the sliding bursts is considered as the deformation instability of the contact surface [21]. During the construction of the Jinping II headrace tunnels, certain structural planes in the vicinity of the tunnels were closely related to the occurrence of rockburst [13]. The excess shear stress (ESS) is used to numerically assess the possible magnitude and relative likelihood of seismic activity induced by fault slip in African mines $[10,22,23]$. The fault-slip events always take place after external disturbances, which can be caused by earthquake, nearby blasting, construction disturbance, and so on [24-27]. Whyatt and Board [26] have reported that $75 \%$ of rockbursts happened on blasting or several hours after blasting. Kie [27], based on the failure mechanism of brittle rocks and the statistical results of practical engineering, pointed out that the rocks can transform from stability to instability while affected by disturbance induced by mining or blasting. Therefore, he stressed that attention should be paid to the triggering effects of dynamic load on the occurrence of rock burst. Interestingly, compared with the released energy, the energy applied by the dynamic load is tiny and negligible [8].

In spite of the many attempts to understand the mechanism of fault-slip bursts, the triggering mechanism for faultslip events induced by external disturbances is still unclear. In this paper, our attentions are mainly paid to investigate the necessary conditions and critical energy conditions of faultslip bursts of the tunnel surrounding rock triggered by external disturbances. Using a self-developed testing system for studying the dynamic behaviour of blocky rock masses, a series of experiments have been conducted for reproducing the sliding instability phenomenon in a blocky rock system subjected to the combined effect of a vertical impact load and horizontal static force. The effects of the vertical impact energy and horizontal static force on the sliding instability are analysed. Further, a one-dimensional dynamic calculation model is established for developing better insight into the mechanism of a slip instability induced by external disturbances. The theoretical analysis and calculations are presented, and it is found that the results agree with the experimental observations. The results provide a theoretical reference on the safety of underground tunnel construction.

\section{Simplified Model and Test System}

2.1. Simplified Model for Sliding Instability in Blocky Rock Systems under External Disturbance. Choosing the rock mass of a tunnel sidewall shown in Figure 1(a) as the research object, the mechanism for triggering shear-slip type disasters in underground openings was investigated. Figure 2 shows the schematic of a physical model test of the block sliding instability under external disturbance in a blocky rock system consisting of five similar blocks stacked from the top to bottom. Of these blocks, the third block (block \#3) was defined as the working block on which the applied horizontal static force acts. In the vertical direction, the block model system was subjected to dynamic disturbance loading. Blocks \#2 and \#4 were horizontally fixed to prevent horizontal sliding. Under different horizontal forces and vertical loadings, the absolute horizontal displacement of block \#3 was measured.

Purple sandstone blocks were adopted in the sliding instability physical model tests. The test model was a vertical block system stacked by five purple sandstone blocks (with dimensions of $160 \times 125 \times 125 \mathrm{~mm}$ and each block weighing $6.2 \mathrm{~kg}$ ). The surfaces between the blocky rock masses were flattened to ensure a close contact and overall stability of the blocky system.

2.2. Test System and Measurement Methods. Based on the test scheme presented above, a new testing system was developed for studying the dynamic behaviour of blocky rock masses. The testing system consisted of a work platform, loading devices, and measurement system. The overall design of the testing device is shown in Figure 3. The work platform was used to hold the blocky rock model with a guide groove in the horizontal direction. Therefore, the horizontal dynamic load device could move along the guide groove to match the different sizes of the blocky rock masses.

The loading devices included horizontal static loading and vertical dynamic loading. The horizontal pulling force applied on block 3 was provided by a wire-wheel-weight plate system. The weights were regulated to set the magnitude of the horizontal pulling force. This was a very simple but effective way to control the horizontal static loading. The vertical dynamic loading was applied with an electrodynamic vibration exciter. A vibration exciter is an electric device that converts electrical energy into mechanical energy, making the excited object to vibrate. Unlike the previous studies using drop weight apparatuses [28, 29], the electrodynamic vibration exciter can precisely control the whole disturbance process, which is convenient for quantitative analysis.

In the experiment, the impact force curve induced by the vibration exciter was measured by the force transducer 


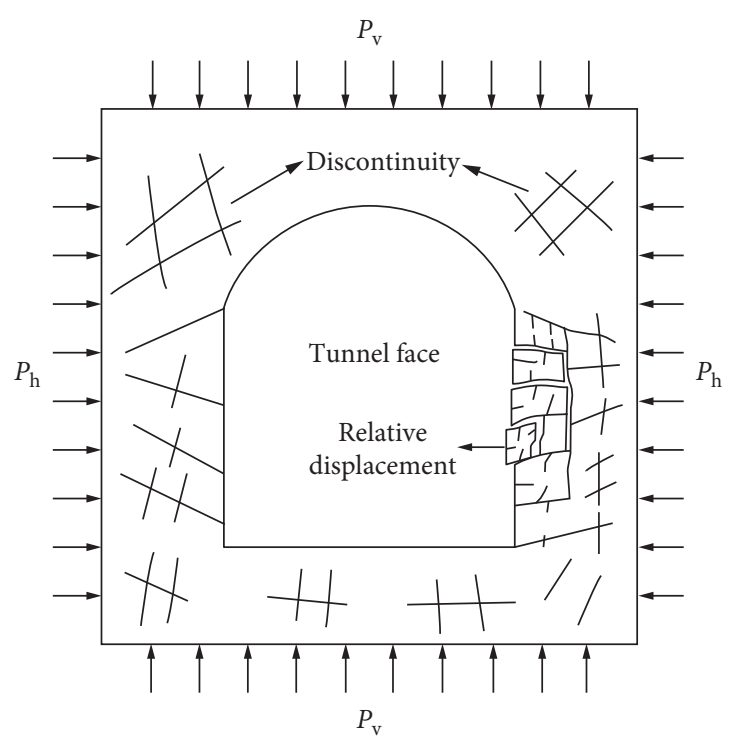

(a)

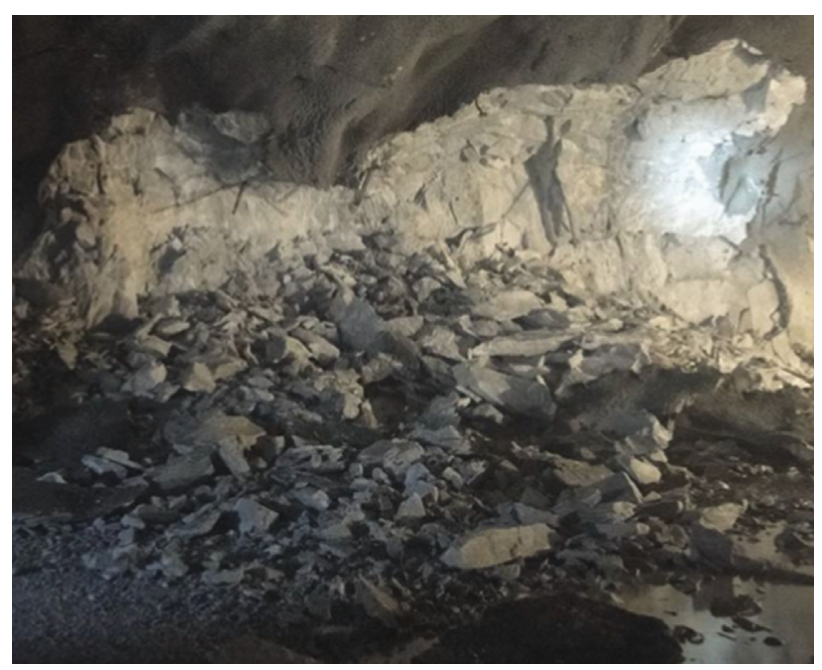

(b)

FIgure 1: Dynamic instability of an underground tunnel: $P_{\mathrm{v}}$ and $P_{\mathrm{h}}$ denote the geostresses. (a) Diagram. (b) Typical field image.

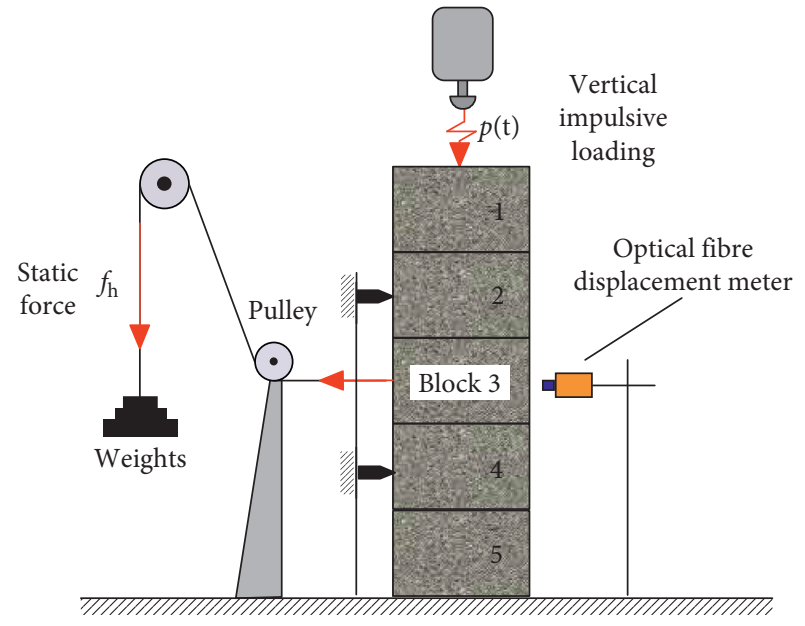

FIGURE 2: Schematic of the triggering sliding instability caused by external disturbance in a blocky rock system.

shown in Figure 4. To accurately measure the absolute displacement of the working block (\#3 block), a fibre-optic displacement sensor (Figure 5) was applied with a sensitivity of $1.1 \mu \mathrm{m} / \mathrm{mV}$, measurement range of $20 \mathrm{~mm}$, and frequency response of $20 \mathrm{kHz}$.

\section{Static Friction Coefficient of \#3 Block}

With the aim to investigate sliding phenomenon of the working block along the structural plane under a static force and an impact load, the maximum static friction $f_{0}$ of the purple sandstone in the blocky system should be first measured.

With the increase in the horizontal force, the frictional force generated between the rock blocks increased. When the two contact surfaces were in a critical state to slip, the

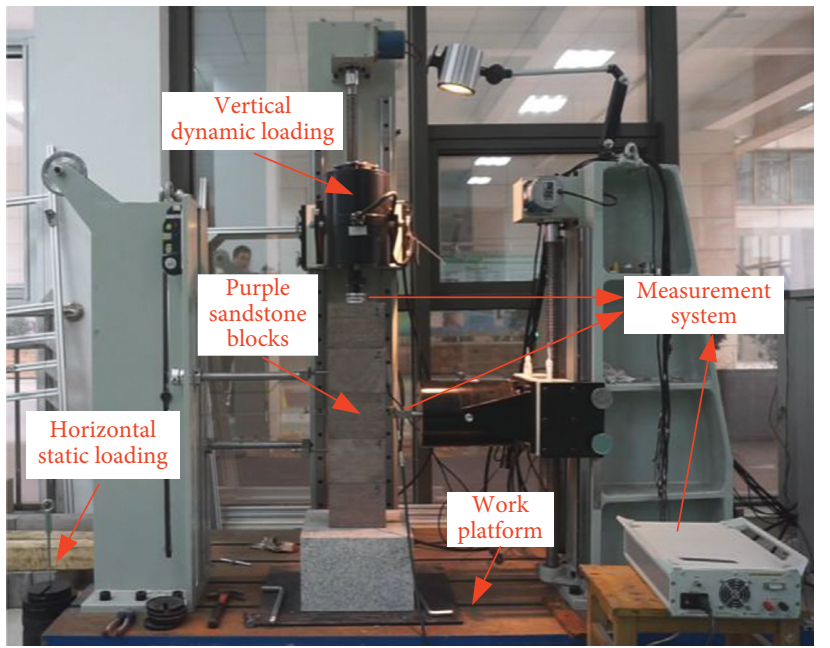

FIGURE 3: Testing system for studying the dynamic behaviour of blocky rock masses.

value of horizontal force was considered the maximum static friction. In the experiments, the horizontal pull was gradually increased by adding weights, and the associated horizontal displacement curve of \#3 block was recorded by the fibre-optic displacement sensor. All the experiments were performed in sets of three to ensure the accuracy of the data. The displacement of the \#3 block displacement versus the horizontal force is shown in Figure 6.

Clearly, the irreversible displacement of the block increases linearly with the horizontal force. When the horizontal pull increases to $200 \mathrm{~N}$, the horizontal displacement of \#3 block increases drastically. Thus, the maximum static friction of \#3 block is $f_{0}=200 \mathrm{~N}$. The working block is subjected to both upper and lower interface friction; that is, the normal force between block $\# 2$ and block \#3 is $2 \mathrm{mg}$ and the normal force 


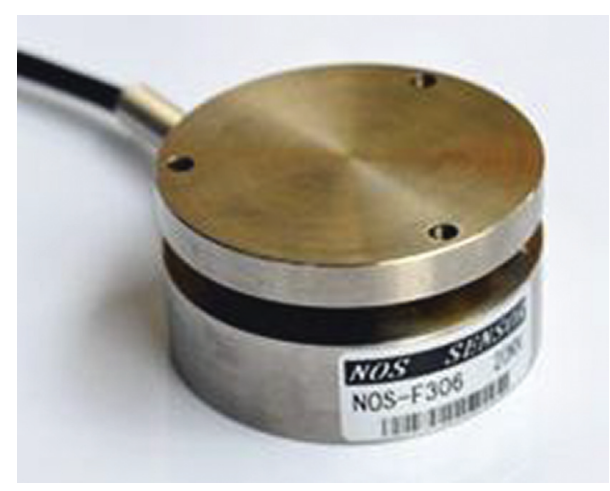

Figure 4: Force transducer.

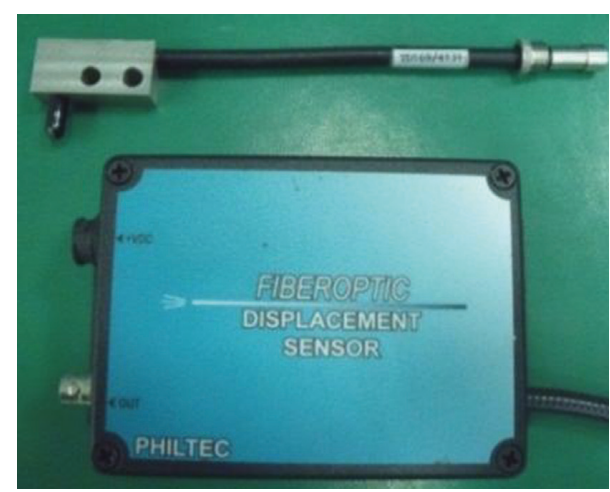

Figure 5: Fibre-optic displacement sensor.

between block \#3 and block \#4 is $3 \mathrm{mg}$. So that the static friction coefficient $\mu_{\mathrm{s}}$ can be calculated as follows:

$$
\mu_{\mathrm{s}}=\frac{f_{0}}{(2 \mathrm{mg}+3 \mathrm{mg})} \approx 0.65,
$$

where $\mu_{\mathrm{s}}$ denotes the static friction coefficient and $g$ is $10 \mathrm{~m} / \mathrm{s}^{2}$.

\section{Combined Effect of Vertical Impact Load and Horizontal Static Force}

4.1. Experimental Procedures. In Section 3, the maximum static friction force of the \#3 block in the blocky system was obtained. In this section, the stability of the blocky system was investigated, which is subjected to the combined effect of a horizontal static force $f_{\mathrm{h}}$ and vertical impact load $p(t)$.

The horizontal pull forces applied on the working block were set as $190,180,170,160,150,130,90$, and $50 \mathrm{~N}$. The external impact energies on the top of the model were chosen as 2, 4, 10, 20,40,80,160, and $300 \mathrm{~mJ}$, until the \#3 block slid freely. In the experiments, the peak disturbing force was increased to obtain a larger disturbance energy. A positive stop device was employed to prevent the collapse of the system; that is, when the working block attains a limited displacement, the motion of the rock mass was stopped.

The force-time curve caused by the vibration exciter was recorded by the force transducer, as shown in Figure 7. The

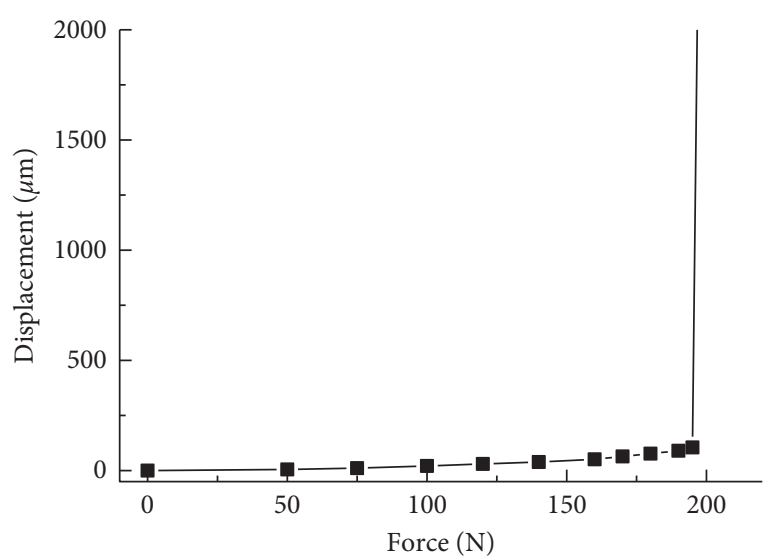

Figure 6: Variation of the displacement as a function of the horizontal pull force.

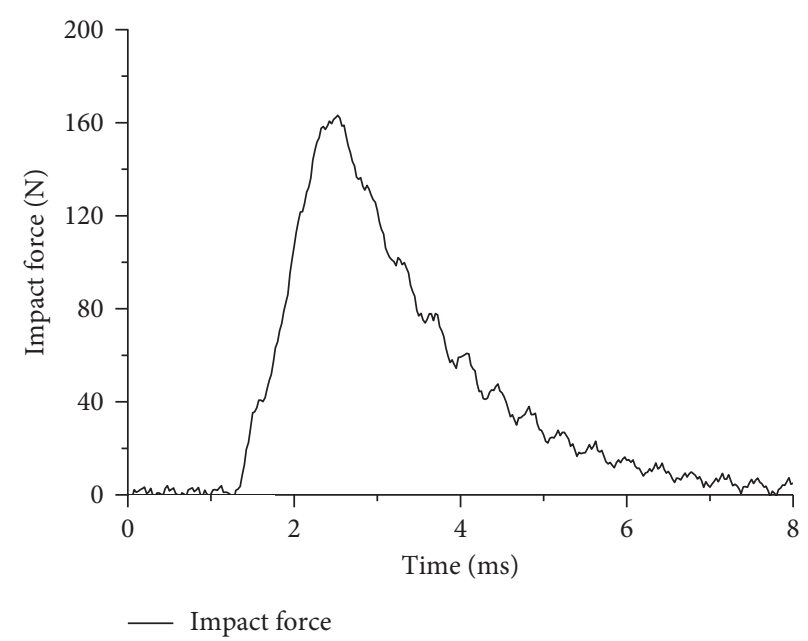

FIgURE 7: Curve of the impact force.

initial velocity of the disturbed block was assumed to be zero, and the disturbance time was considerable short. Then, the relation between the impulse $I_{\mathrm{m}}$ and the disturbance energy $W$ was deduced as follows:

$$
W=\frac{1}{2 m}\left|\int_{0}^{\infty} p(t) d t\right|^{2}=\frac{I_{\mathrm{m}}^{2}}{2 m},
$$

where $p(t)$ represents force-time curve.

4.2. Experimental Results. The horizontal displacement of the working block was recorded by a fibre-optic displacement sensor. Figure 8 shows the displacement-time curves of the working block under a combined effect of different vertical impact loads and horizontal static forces.

The experimental results shown in Figure 8 can be described as follows:

First, for a given horizontal static force, the horizontal residual displacement of the working block increases with increasing vertical impact energy. Considering Figure 8(b) as an example, where the horizontal pull force is $180 \mathrm{~N}$, the residual displacements of \#3 block are 94, 374, and $700 \mu \mathrm{m}$, 

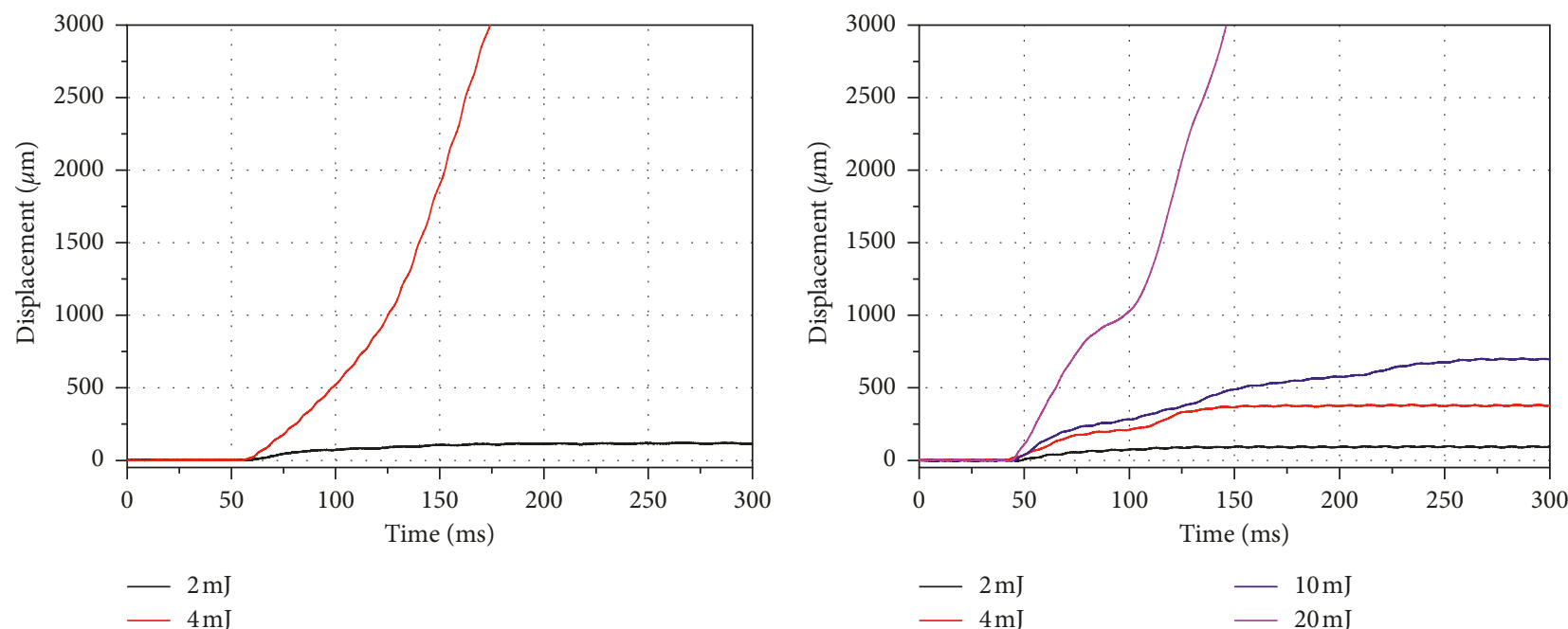

(a)
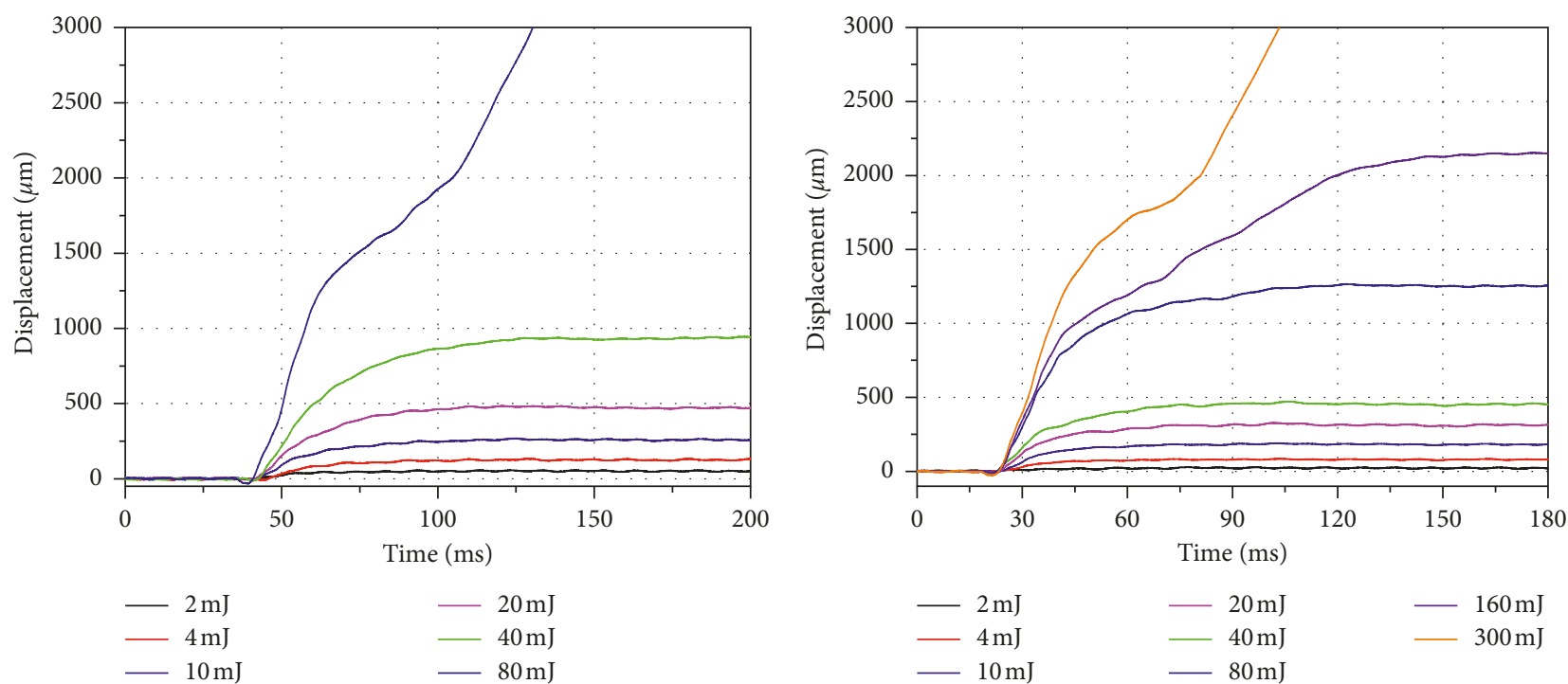

(c)

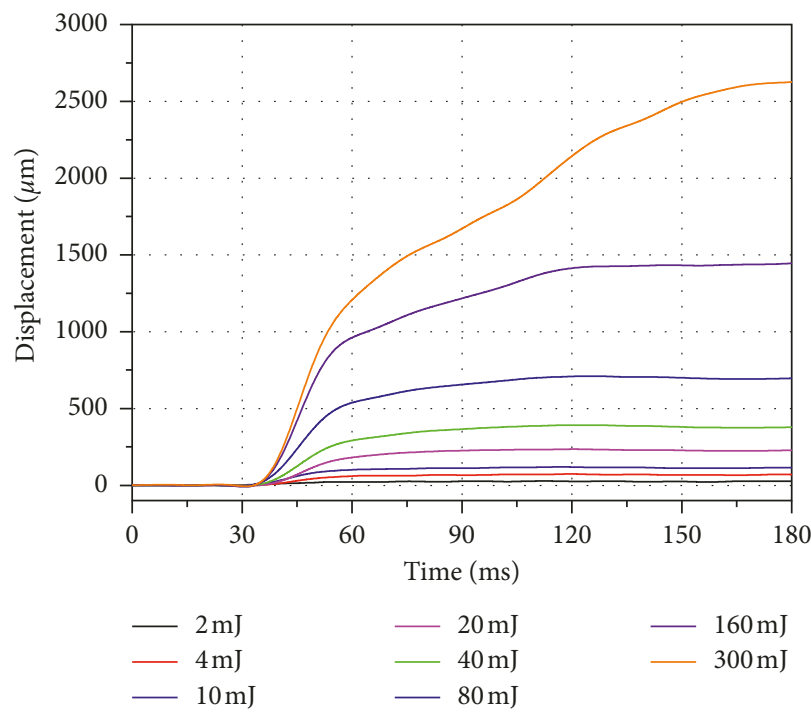

(d)
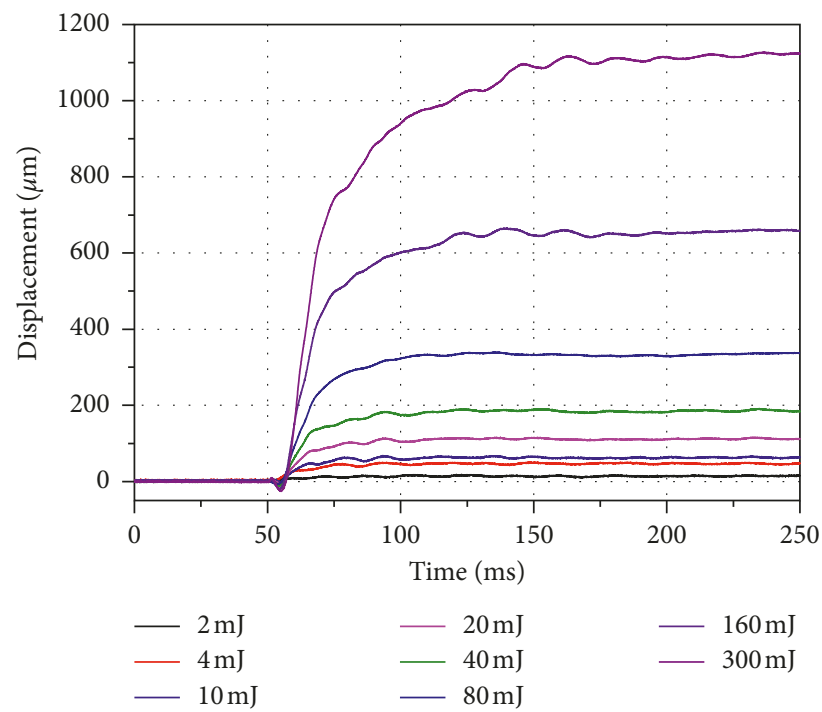

(e)

(f)

Figure 8: Continued. 


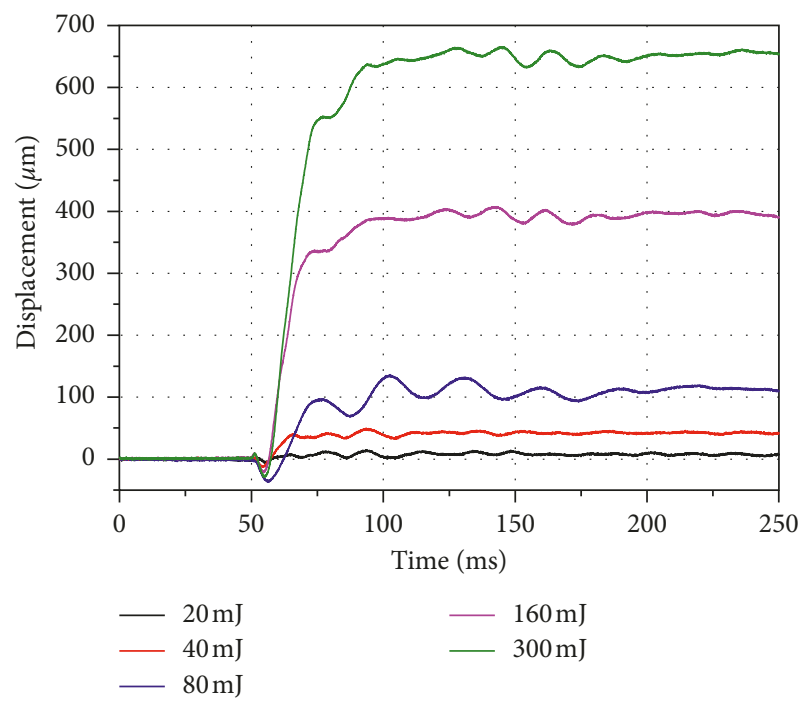

$(\mathrm{g})$

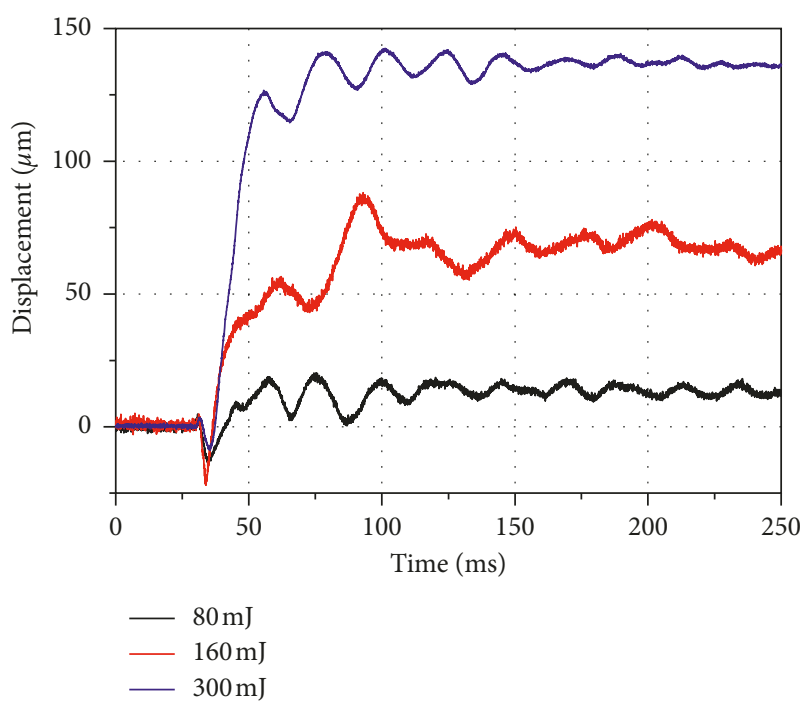

(h)

Figure 8: Displacements of block \#3 under the joint action of a vertical impact load and horizontal force. (a) $f_{\mathrm{h}}=190 \mathrm{~N}$. (b) $f_{\mathrm{h}}=180 \mathrm{~N}$. (c) $f_{\mathrm{h}}=170 \mathrm{~N}$. (d) $f_{\mathrm{h}}=160 \mathrm{~N}$. (e) $f_{\mathrm{h}}=150 \mathrm{~N}$. (f) $f_{\mathrm{h}}=130 \mathrm{~N}$. (g) $f_{\mathrm{h}}=90 \mathrm{~N}$. (h) $f_{\mathrm{h}}=50 \mathrm{~N}$.

corresponding to the impact energies of 2, 4, and $10 \mathrm{~mJ}$, respectively. According to the experimental data, Figure 9 shows the influence of the vertical impact energy on the displacement of \#3 block with the horizontal static force ranging from 50 to 190 N. As shown in Figure 9, it was found that the block system became increasingly sensitive to the disturbance energy as the horizontal static force increased. When the horizontal static force was close to the peak static friction force, the displacements strongly depended on the disturbance energy, and even a considerably small disturbance was capable of causing a large irreversible displacement.

Second, in the case of an impact energy of $4 \mathrm{~mJ}$ and horizontal pull force of $190 \mathrm{~N}$ (Figure 8(a)), the working block slides freely, implying that the sliding instability phenomenon occurs. The same phenomena are similarly observed in Figures 8(b)-8(d), and the vertical impact energies of impact load triggering sliding instability are 20,80 , and $300 \mathrm{~mJ}$, corresponding to the horizontal static force of 180 (Figure 8(b)), 170 (Figure 8(c)), and 160 N (Figure 8(d)), respectively.

Finally, when the horizontal shear force decreases to a certain threshold, regardless of how the impact energy increases, there is only an irreversible displacement between the rock blocks, and the slip instability does not occur. For example, when the working rock mass is reduced horizontally to $F=150 \mathrm{~N}$ (Figure 8(e)), even if we increase the impact energy to $300 \mathrm{~mJ}$, the \#3 block does not slip out, and only an irreversible displacement of $2640 \mu \mathrm{m}$ occurs. According to the subsequent theoretical analysis, this critical threshold agrees with the dynamic friction between the block rock mass. System. We have attempted to present the mechanism of the

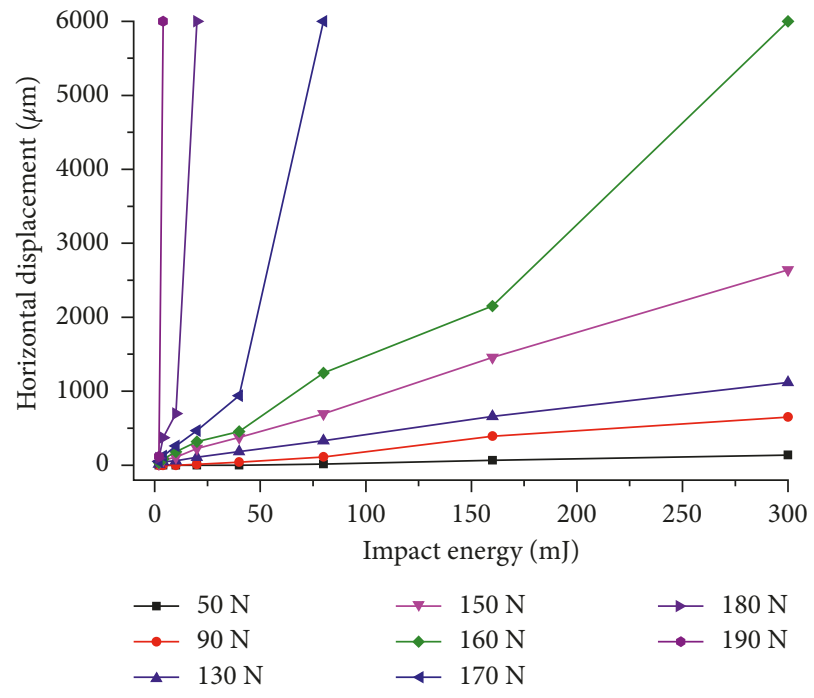

Figure 9: Horizontal displacement versus impact energy for \#3 block.

irreversible displacements, induced by the vertical impact disturbances, occurring in the blocky rock mass. In the experiment, the impact load applied to the blocky rock model can be approximately regarded as a one-dimensional wave propagation. During this process, the total normal stress between the blocky rock interfaces increases when the dynamic compression phase passes, and the normal stress $\sigma$ decreases when the tension phase passes, compared to the original static stress. Considering there are no fillings between the rock masses in experiment, the cohesion $C \approx 0$; hence, the shear strength $\tau_{\mathrm{p}}$ is mainly proportional to the normal stress $\sigma\left(\tau_{\mathrm{p}}=\mu \cdot \sigma\right)$. Therefore, when the dynamic stress is compressive, the shear strength increases, and when the dynamic stress is tensile, the shear strength decreases. 
If the ratio of the constant shear stress $\tau$ to the shear strength $\tau_{\mathrm{p}}$ exceeds the critical value of $\tau / \tau_{\mathrm{p}}=1$, the sliding of the rock block along with its interface occurs. Furthermore, during the process of shear deformation, the shear strength decreases more significantly because the friction coefficient $\mu$ reduces from the static friction coefficient $\mu_{\mathrm{s}}$ to the dynamic friction coefficient $\mu_{\mathrm{d}}$, which presents the product effect. Thus, when $\tau / \tau_{\mathrm{p}}>1$ is satisfied, the relative motion of the block is accelerated; otherwise, the relative motion slows down. Furthermore, during the process of the onedimensional impact load, dynamic sliding of the blocks along the structural plane occurs intermittently, as confirmed by Figure 8 .

\section{Dynamic Calculation Model of Induced Slip Instability of Block Rock}

The above experimental results show that an irreversible slippage occurs even if the sliding instability of the working rock under dynamic actions is closely related to the dynamic deformation and friction characteristics of the block interface. It is essential to understand the normal and tangential dynamic responses of an interface to dynamic actions. Based on this, a one-dimensional calculation model was established for gaining better insight into the mechanism of the slip instability induced by external disturbances.

5.1. Establishment and Solution of Motion Equations. A rock mass is a complex structural system in which the rock blocks are nested with each other and interconnected by a middle layer of weaker and fractured rocks. A model of a chain of masses connected by elastic springs and damping elements is proposed [30,31], as shown in Figure 10(a). The entire blocky rock system as a whole is affected by the external dynamic force $p(t)$ that can be represented as a half-sine load:

$$
p(t)= \begin{cases}p_{\mathrm{m}} \sin \omega t, & 0 \leq t \leq T, \\ 0, & t \geq T,\end{cases}
$$

where $T$ denotes the duration of impact load, $\omega$ is the angular velocity $(\omega=\pi / T), p_{\mathrm{m}}$ denotes the peak force, and $f_{\mathrm{h}}$ is a horizontal static force representing a lateral force applied to the working block.

The dynamic equations of the blocky rock structure can be expressed in a matrix form as

$$
\mathbf{M} \ddot{y}(t)+\mathbf{C} \dot{y}(t)+\mathbf{K} \mathbf{y}(t)=\mathbf{p}(t),
$$

where $\mathbf{M}$ is the mass matrix, $\mathbf{M}=\left[\begin{array}{ccc}m_{1} & & \\ & m_{2} & \\ & \ddots & \\ & & m_{5}\end{array}\right], \mathbf{y}(t)$ is the displacement vector, $\mathbf{y}(t)=\left\{\begin{array}{c}y_{1} \\ y_{2} \\ \vdots \\ y_{5}\end{array}\right\}, \mathbf{C}$ is the damping matrix, $\mathbf{C}=\left[\begin{array}{ccccc}c_{1} & -c_{1} & & & \\ -c_{1} & c_{1}+c_{2} & -c_{2} & & \\ & -c_{2} & c_{2}+c_{3} & -c_{3} & \\ & & -c_{3} & c_{3}+c_{4} & -c_{4} \\ & & & -c_{4} & c_{4}+c_{5}\end{array}\right], \quad \mathbf{K} \quad$ is

the stiffness matrix,

$\mathbf{K}=\left[\begin{array}{ccccc}k_{1} & -k_{1} & & & \\ -k_{1} & k_{1}+k_{2} & -k_{2} & & \\ & -k_{2} & k_{2}+k_{3} & -k_{3} & \\ & & -k_{3} & k_{3}+k_{4} & -k_{4} \\ & & & -k_{4} & k_{4}+k_{5}\end{array}\right]$, and $\mathbf{p}(t)$ is the vertical loading vector, $\mathbf{p}(t)=\left\{\begin{array}{c}p(t) \\ 0 \\ \vdots \\ 0\end{array}\right\}$.

For the working block subjected to a horizontal static force $f_{\mathrm{h}}$ (Figure 10(b)), the equation of motion is

$$
m \ddot{x}=f_{\mathrm{h}}-\mu\left(N_{2,3}(t)+N_{3,4}(t)\right),
$$

where $x$ and $\ddot{x}$ are the horizontal displacement and acceleration of the working block, respectively, $N_{2,3}(t)$ is the normal force between block \#2 and block \#3, $N_{3,4}(t)$ is the changing normal force between block \#2 and block \#3, and $\mu$ is the friction coefficient of the blocky rock.

It is accepted that sliding of the blocky rock mass is initiated when the ratio of the shear to normal stress on the surface attains a value $\mu_{\mathrm{s}}$, referred as the static friction coefficient. Once the sliding initiates, the frictional resistance decreases and has a lower dynamic friction coefficient $\mu_{\mathrm{d}}$. The weakening of the sliding resistance is closely related to the microstructure, normal stress, temperature, and sliding velocity and may result in a dynamic instability $[18,32]$. It is to be noted that the focus of this study is not on determining the mechanism of this problem. Here, only the velocity weakening behaviour of the friction coefficient is considered, and it can be expressed as [33]

$$
\mu= \begin{cases}\mu_{\mathrm{s}}, & v \leq v_{\mathrm{m}}, \\ \mu_{\mathrm{d}}+\left(\mu_{\mathrm{s}}-\mu_{\mathrm{d}}\right) * \frac{v_{\mathrm{m}}}{v}, & v \geq v_{\mathrm{m}},\end{cases}
$$

where $v$ is the sliding velocity, $v_{\mathrm{m}}$ is the critical velocity, and $v_{\mathrm{m}}=1 \times 10^{-2} \mathrm{~m} / \mathrm{s}$.

5.2. Calculation Results. Considering the purple sandstone block in the above experiment as the object of calculation, the mass $m=6.2 \mathrm{~kg}$, the static friction coefficient $\mu_{\mathrm{s}}=0.65$, dynamic friction coefficient $\mu_{\mathrm{d}}=0.5$, assumed spring stiffness $k=3 \times 10^{6} \mathrm{~N} / \mathrm{m}$, and damping $c=2.5 \times 10^{3} \mathrm{~N} \cdot \mathrm{s} / \mathrm{m}$ were employed $[34,35]$. The theoretical result of the sliding of the working block thereby obtained is shown in Figure 11, where a horizontal constant pull force of $f_{\mathrm{h}}=160 \mathrm{~N}$, series of a half-sine load with different magnitudes of the peak force $p_{\mathrm{m}}$, and duration of vertical action $T=4 \mathrm{~ms}$ and $\omega=$ $250 \pi$ are used.

For a given acceleration-time curve, when the acceleration is higher than zero (Figure 11(a)), the velocity of the 


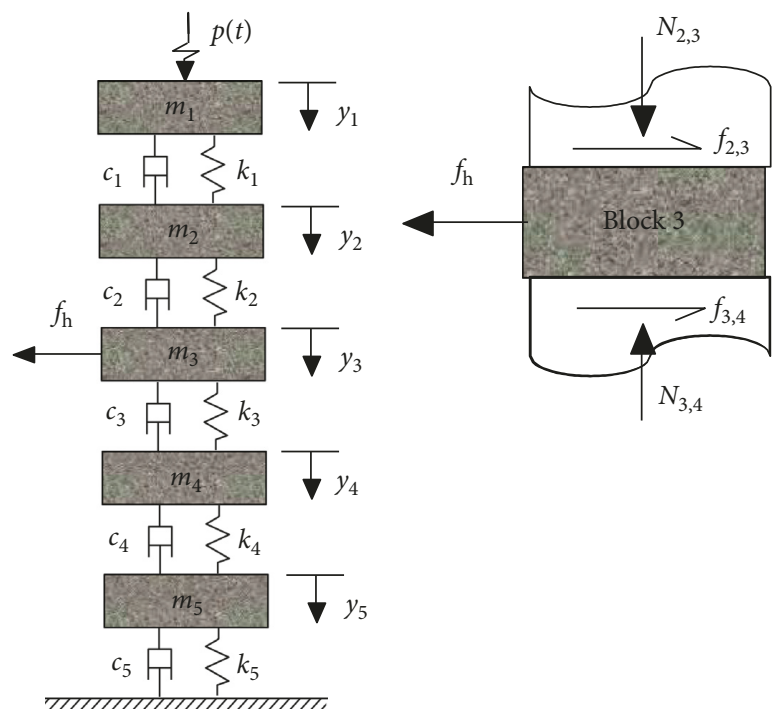

(a)

(b)

FIGURE 10: Modelling and analysis of the blocky rock system. (a) Analytical model in vertical direction [31]. (b) Mechanical analysis of \#3 block.

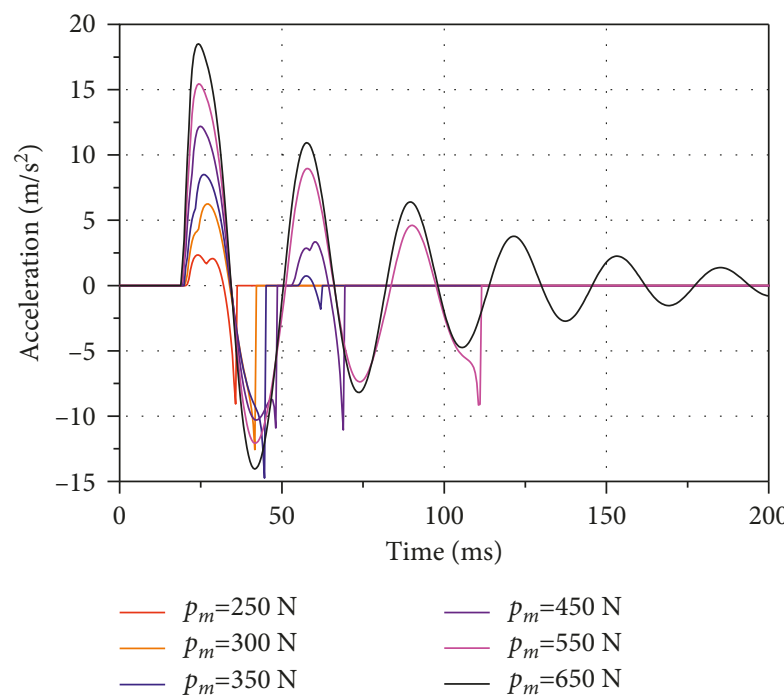

(a)

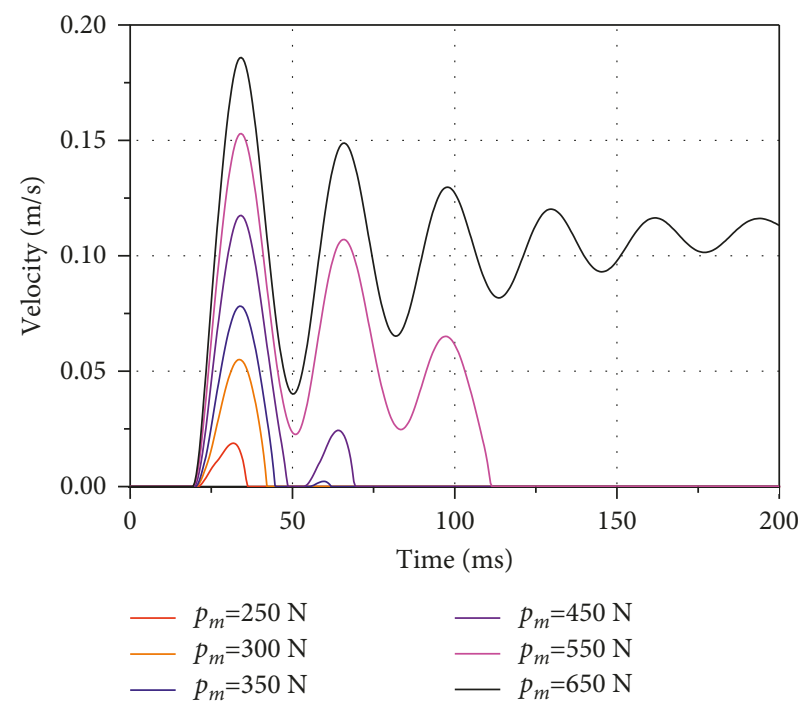

(b)

FIgUre 11: Continued. 


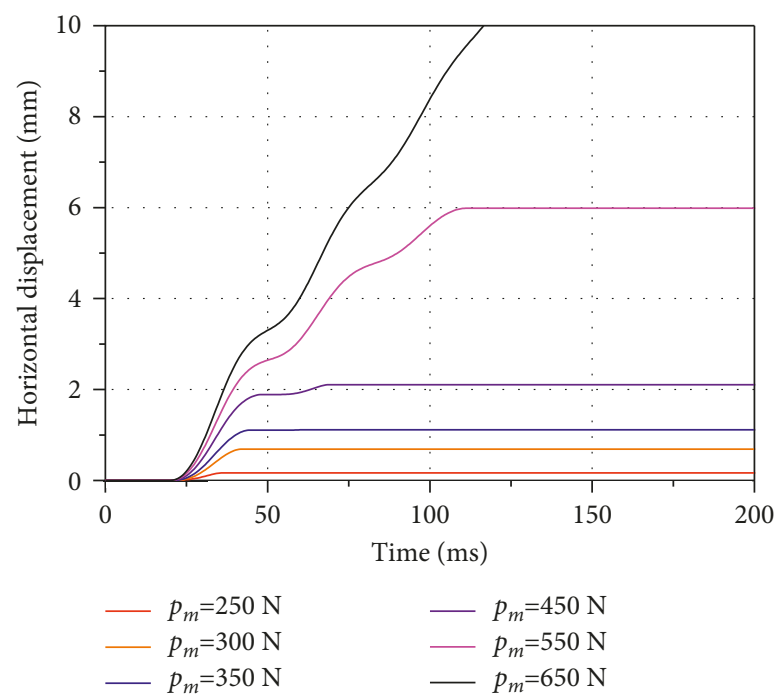

(c)

FIGURE 11: Theoretical results of the sliding displacement of the working block ( $\left.f_{\mathrm{h}}=160 \mathrm{~N}\right)$. (a) Acceleration time histories. (b) Velocity time histories. (c) Displacement time histories.

block increases (Figure 11(b)) and the block starts to slide (Figure 11(c)). The velocity of the block is obtained by integrating the acceleration-time curve and the displacement is calculated by integrating the velocity-time curve. When the acceleration is less than zero, the velocity of the block decreases, but the displacement continually increases until the velocity decreases to zero. The above process repeats several times until the acceleration is no longer larger than zero. It can be seen from Figure 11 that the irreversible displacement of the \#3 block rock mass increases with an increase in the vertical impact disturbance, for a given constant horizontal force. When the impact disturbance exceeds a critical value $\left(p_{\mathrm{m}}=650 \mathrm{~N}\right)$, the working block slips freely, indicative of the sliding instability of the blocky structure.

Furthermore, the theoretical result of the effects of the vertical impact load on the sliding instability is presented in Figure 12, where the solid lines represent the theoretical results, and the scatter symbols represent the experimental results shown in Figure 9. Compared with the experimental results, it can be found that theoretical result can well describe fault-slip events induced by external disturbance.

5.3. Critical Energy Condition of Fault Sliding Events. A dimensionless energy parameter $I$ is introduced to characterize the energy conditions for fault-slip events and can be expressed as [36]

$$
I=\frac{W}{\tau_{s} V}=\frac{W}{f_{0} H}
$$

where $\tau_{\mathrm{s}}$ denotes the static shear strength, $V$ is the volume of the rock block, and $H$ is the height of the rock block.

Figure 13 shows the critical values of the block system required to obtain irreversible displacements and sustained slip failures in experiments. The round symbols and square symbols represent the experimental results, while the solid

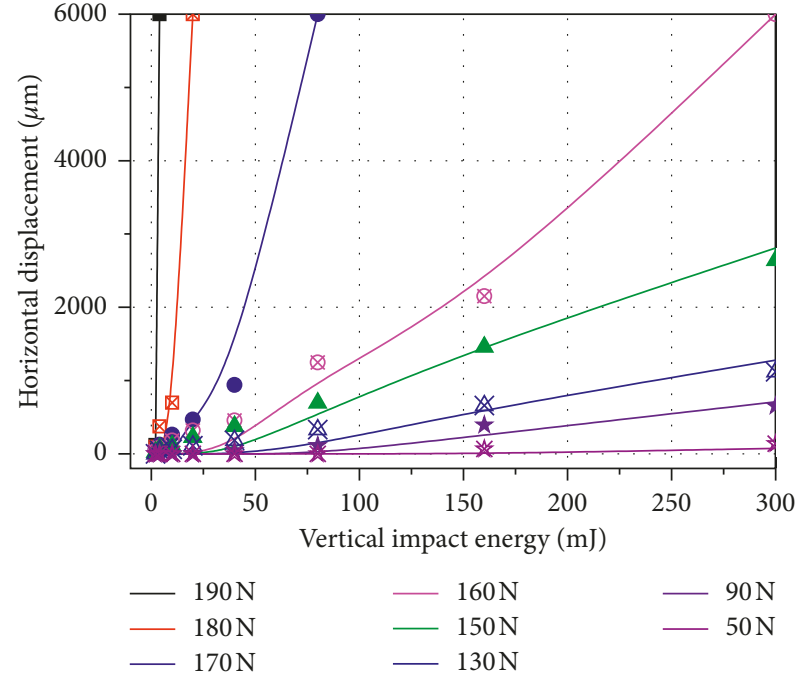

Figure 12: Theoretical results of the slip trend and critical combination condition.

lines represent the calculation results. The dotted line represents the supplementary boundary for zone III. In Figure 13, there are three zones that represent different statuses of the work block after the vertical dynamic disturbance loads. In zone $\mathrm{I}$, the horizontal pulling force $f_{\mathrm{h}}$ cannot exceed the peak static friction force $f_{0}$ from the beginning to end, and no apparent displacement in horizontal direction aside from that of elastic deformation can be observed. In zone II, the horizontal pulling force is too low or the impact energy is not large enough to cause a sustained slip failure, and irreversible displacements can be observed. In zone III, both the horizontal pulling force $f_{\mathrm{h}}$ exceeds the dynamic friction force and the impact energy is large enough, and the work block cannot stop slipping, which may cause slip type rock bursts or other engineering hazards. 


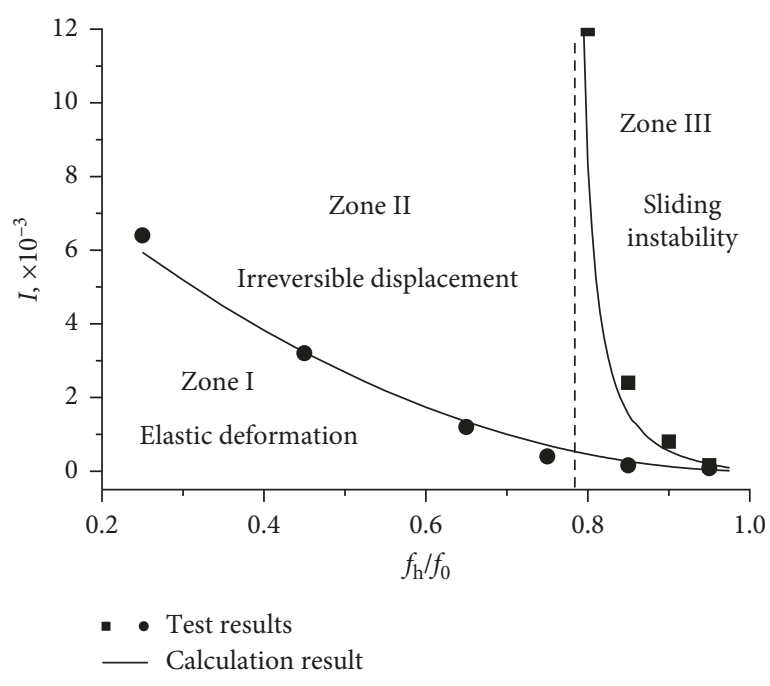

Figure 13: Critical energy conditions of fault sliding events.

Thus, the calculation results are consistent with the experimental results, validating the feasibility of this calculation model. The dimensionless energy parameter in Equation (7) is an important characteristic parameter that can reflect the relationship between the external disturbance and the stability of the rock blocks.

\section{Conclusion}

To study the initiation mechanism of shear-slip type disasters occurring in underground openings, a series of experiments were performed to investigate the triggering of the sliding instability phenomenon in blocky rock system. In addition, the corresponding theoretical analysis and calculations were conducted. The primary conclusions of this study can be summarized as follows:

(1) A new test system for studying the dynamic behaviour of blocky rock masses was designed and developed, including the sliding of blocky rock masses along the structural plane and onedimensional wave propagation characteristics. This test system exhibited several advantages such as shorter experimental periods, convenience, and high reliability and efficiency.

(2) A series of experiments were conducted to reproduce the sliding instability phenomenon in a blocky rock system that was subjected to the combined effect of a vertical impact load and horizontal static force. The experimental results showed that the critical energy of the impact load triggering the slip instability depended on the level of shear force; the higher the shear force, the lower was the external disturbance required.

(3) A one-dimensional dynamic calculation model was established to gain better insight into the mechanism of the slip instability induced by external disturbances. A dimensionless energy parameter was introduced to quantifiably characterize the critical conditions of different types of fault-slip events. Theoretical analyses and calculations were presented, and the results agreed with the experimental observations.

In conclusion, a shear-slip type rockburst is characterised by contact instability. The main factors influencing the slip rockburst include the property of the contact surface, stress state, and external dynamic disturbances. The triggering mechanism of this dynamic phenomenon is that when the rock mass structure is a high shear stress state, the external disturbance helps the rock mass overcome the frictional resistance, facilitating the sliding of the key block from the constraint.

\section{Conflicts of Interest}

The authors declare that they have no conflicts of interest.

\section{Acknowledgments}

This study was supported by the Major Research Plan of the National Natural Science Foundation of China (Grant no. 51527810) and National Natural Science Foundation of China (Grant no. 51679249).

\section{References}

[1] C. Q. Zhang, X. T. Feng, H. Zhou, S. Qiu, and W. Wu, "Case histories of four extremely intense rockbursts in deep tunnels," Rock Mechanics and Rock Engineering, vol. 45, pp. 275-288, 2012.

[2] H. Zhou, F. Z. Meng, C. Q. Zhang, D. Hu, F. Yang, and J. Lu, "Analysis of rockburst mechanisms induced by structural planes in deep tunnels," Bulletin of Engineering Geology and the Environment, vol. 74, pp. 1435-1451, 2015.

[3] X. F. Shi, F. X. Jiang, S. T. Zhu, and G. Yang, "Mechanism of integrated dynamic disaster of rockburstand water inrush: a new type of integrated dynamic disaster in China," Geotechnical and Geological Engineering, vol. 35, no. 3, pp. 1261-1270, 2017.

[4] N. G. W. Cook, E. Hoek, J. P. G. Pretorius et al., "Rock mechanics applied to the study of rockbursts," Journal South African Institute of Mining and Metallurgy, vol. 66, pp. 435528, 1966.

[5] W. Blake and D. G. F. Hedley, Rockbursts: Case Studies from North American Hard-Rock Mines, Society for Mining, Metallurgy, and Exploration, New York, NY, USA, 2003.

[6] W. D. Ortlepp and T. R. Stacey, "Rockburst mechanisms in tunnels and shafts," Tunnelling and Underground Space Technology, vol. 9, pp. 59-65, 1994.

[7] P. K. Kaiser and M. Cai, "Design of rock support system under rockburst condition," Journal of Rock Mechanics and Geotechnical Engineering, vol. 4, no. 3, pp. 215-227, 2012.

[8] M. C. He, H. M. Xia, X. N. Jia, W. Gong, F. Zhao, and K. Liang, "Studies on classification, criteria and control of rockbursts," Journal of Rock Mechanics and Geotechnical Engineering, vol. 4, pp. 97-114, 2012.

[9] T. R. Stacey, "Support of excavations subjected to dynamic (rockburst) loading," in Proceedings of the 12th International Congress of the International Society of Rock Mechanics, pp. 137-145, Beijing, China, 2011.

[10] J. A. Ryder, "Excess shear stress in the assessment of geologically hazardous situations," Journal South African Institute of Mining and Metallurgy, vol. 88, pp. 27-39, 1988. 
[11] M. C. He, W. Nie, Z. Y. Zhao, and W. Guo, "Experimental investigation of bedding plane orientation on the rockburst behavior of sandstone," Rock Mechanics and Rock Engineering, vol. 45, pp. 311-326, 2012.

[12] Z. L. Li, L. M. Dou, W. Cai et al., "Investigation and analysis of the rock burst mechanism induced within fault-pillars," International Journal of Rock Mechanics and Mining Sciences, vol. 70, pp. 192-200, 2014.

[13] H. Zhou, F. Z. Meng, C. Q. Zhang, D. Hu, F. Yang, and J. Lu, "Analysis of rockburst mechanisms induced by structural planes in deep tunnels," Bulletin of Engineering Geology and the Environment, vol. 74, pp. 1435-1451, 2015.

[14] B. G. He, R. Zelig, Y. H. Hatzor, and X.-T. Feng, "Rockburstgeneration in discontinuous rock masses," Rock Mechanics and Rock Engineering, vol. 49, pp. 4103-4124, 2016.

[15] F. Z. Meng, H. Zhou, Z. Q. Wang et al., "Experimental study of factors affecting fault slip rockbursts in deeply buried hard rock tunnels," Bulletin of Engineering Geology and the Environment, vol. 76, no. 3, pp. 1167-1182, 2016.

[16] F. Z. Meng, H. Zhou, Z. Q. Wang et al., "Experimental study on the prediction of rockburst hazards induced by dynamic structural plane shearing in deeply buried hard rock tunnels," International Journal of Rock Mechanics and Mining Sciences, vol. 86, pp. 210-223, 2016.

[17] J. Zhou, X. Li, and H. S. Mitri, "Classification of rockburst in underground projects: comparison of ten supervised learning methods," Journal of Computing in Civil Engineering, vol. 30, article 04016003, 2016.

[18] E. V. Shilko, S. V. Astafurov, V. V. Ruzhich, and S. G. Psakhie, "On the feasibility of shear stress estimation at interfaces of block-structured medium," Physical Mesomechanics, vol. 13, pp. 21-27, 2010.

[19] A. S. Grigoriev, E. V. Shilko, S. V. Astafurov et al., "Effect of dynamic stress state perturbation on irreversible strain accumulation at interfaces in block-structured media," Physical Mesomechanics, vol. 19, pp. 136-148, 2016.

[20] C. Z. Qi, C. S. Chen, Q. H. Qian, and J. Luo, "Dynamic instability of tunnel in blocky rock mass," Transactions of Tianjin University, vol. 14, pp. 457-463, 2008.

[21] M. D. G. Salamon, "Stability, instability and design of pillar workings," International Journal of Rock Mechanics and Mining Science \&Geomechanics Abstracts, vol. 7, pp. 613-631, 1970.

[22] S. M. Spottiswoode, "Perspectives on seismic and rockburst research in the south african gold mining industry: 19831987," Pure \& Applied Geophysics, vol. 129, pp. 673-680, 1989.

[23] J. A. L. Napier, "Application of excess shear stress to the design of mine layouts," Journal of the South African Institute of Mining \& Metallurgy, vol. 87, no. 12, pp. 397-405, 1987.

[24] D. P. Hill, P. A. Reasenberg, A. Michael et al., "Seismicity remotely triggered by the magnitude 7.3 landers, California, earthquake," Science, vol. 260, pp. 1617-1623, 1993.

[25] P. Yan, Z. Zhao, W. Lu, Y. Fan, X. Chen, and Z. Shan, "Mitigation of rock burst events by blasting techniques during deep-tunnel excavation," Engineering Geology, vol. 188, pp. 126-136, 2015.

[26] J. K. Whyatt and M. P. Board, "Strain softening model for representing shear failure in continuous rock masses: Proc 2nd International Symposium on Rockbursts and Seismicity in Mines, Minneapolis, 8-10 June 1988, p61-64. publRotterdam: a Balkema, 1990," International Journal of Rock Mechanics \& Mining Sciences \& Geomechanics Abstracts, vol. 28, pp. A341-A342, 1991.
[27] T. T. Kie, "Rockbursts, case records, theory and control," in Proceedings of the International Symposium on Engineering in Complex Rock Formations, pp. 32-47, 1987.

[28] M. V. Kurlenya, V. N. Oparin, and V. I. Vostrikov, "Effect of anomalously low friction in block media," Journal of Applied Mechanics \& Technical Physics, vol. 40, pp. 1116-1120, 1999.

[29] H. L. Wang, T. Ge, D. R. Wang et al., "Comparison of theoretical and experimental analysis of dynamic characteristics of block rock mass," Chinese Journal of Rock Mechanics and Engineering, vol. 26, pp. 951-958, 2007, in Chinese.

[30] N. I. Aleksandrova, A. G. Chernikov, and E. N. Sher, "On attenuation of pendulum-type waves in a block rock mass," Journal of Mining Science, vol. 42, pp. 468-475, 2006.

[31] G. W. Ma, X. M. An, and M. Y. Wang, "Analytical study of dynamic friction mechanism in blocky rock systems," International Journal of Rock Mechanics \& Mining Sciences, vol. 46, pp. 946-951, 2009.

[32] M. L. Blanpied, T. E. Tullis, and J. D. Weeks, "Effects of slip, slip rate, and shear heating on the friction of granite," Journal of Geophysical Research, vol. 103, pp. 489-511, 1998.

[33] N. M. Beeler and T. E. Tullis, "The roles of time and displacement in velocity-dependent volumetric strain of faults," Journal of Geophysical Research, vol. 102, pp. 22595-22609, 1997.

[34] N. I. Aleksandrova, A. G. Chernikov, and E. N. Sher, "Experimental investigation into the one-dimensional calculated model of wave propagation in block medium," Journal of Mining Science, vol. 41, no. 3, pp. 232-239, 2005.

[35] N. I. Aleksandrova, E. N. Sher, and A. G. Chernikov, "Effect of viscosity of partings in block-hierarchical media on propagation of low-frequency pendulum waves," Journal of Mining Science, vol. 44, no. 3, pp. 225-234, 2008.

[36] M. Y. Wang, J. Li, L. J. Ma et al., "Study on the characteristic energy factor of the deep rock mass under weak disturbance," Rock Mechanics and Rock Engineering, vol. 49, pp. 3165-3173, 2016. 


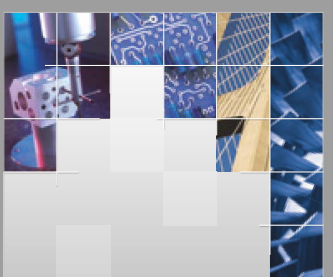

\section{Enfincering}
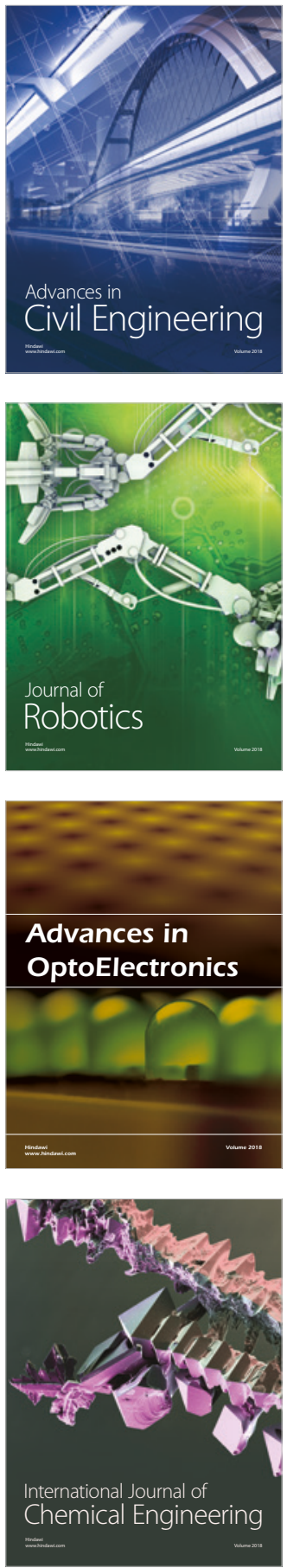

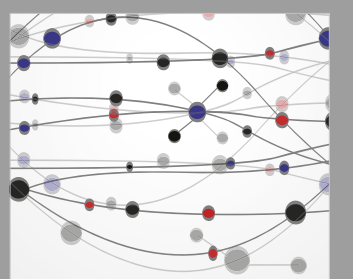

\section{Rotating \\ Machinery}

The Scientific World Journal

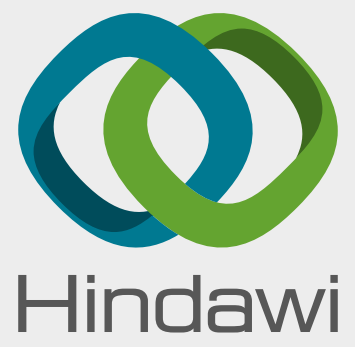

Submit your manuscripts at

www.hindawi.com
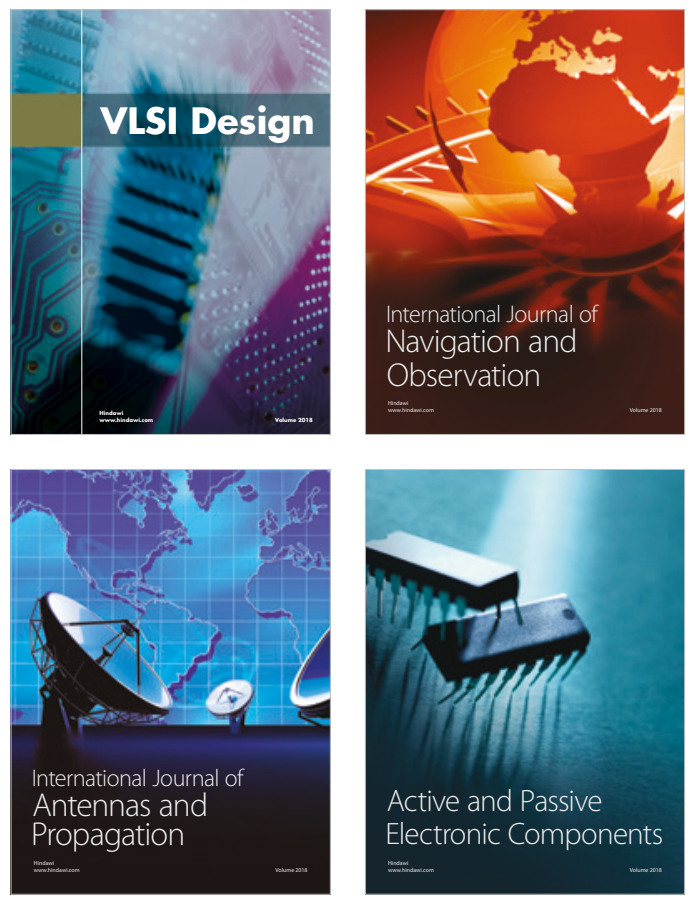
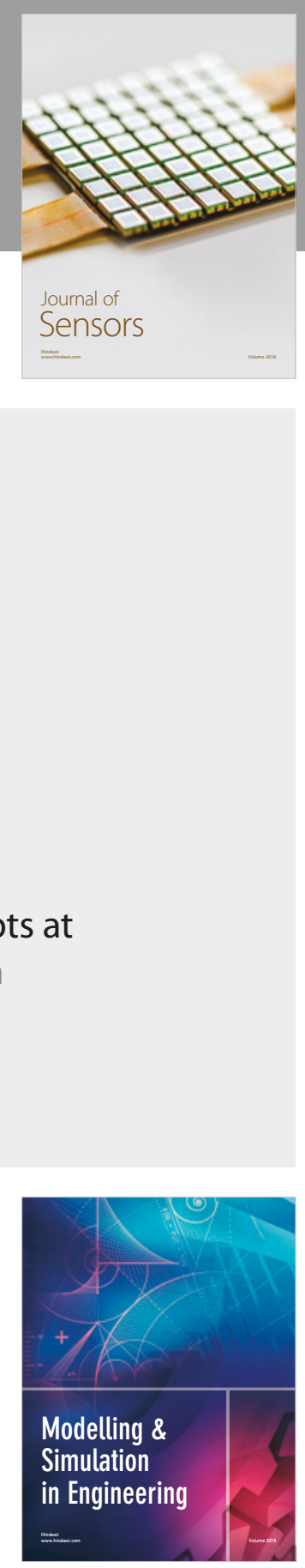

\section{Advances \\ Multimedia}
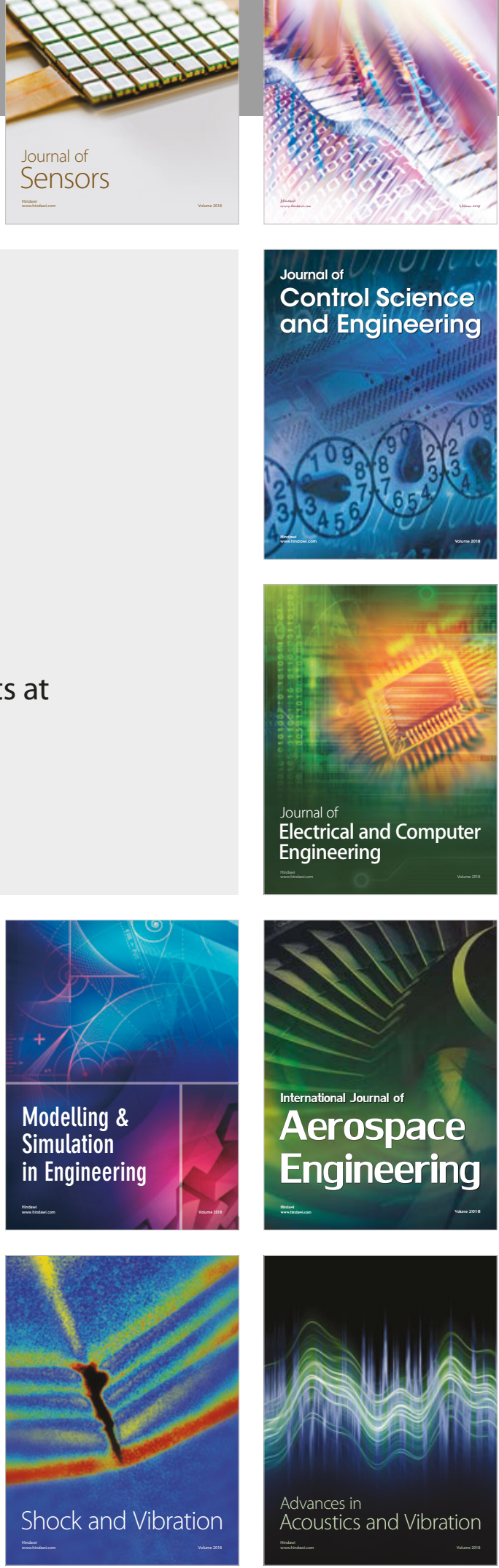